ISSN 1561-8358 (Print)

ISSN 2524-244X (Online)

ЭНЕРГЕТИКА, ТЕПЛО- И МАССООБМЕН

POWER ENGINEERING, HEAT AND MASS TRANSFER

УДК 621.565.943.2

https://doi.org/10.29235/1561-8358-2020-65-2-215-223

Поступила в редакцию 16.02.2020

Received 16.02.2020

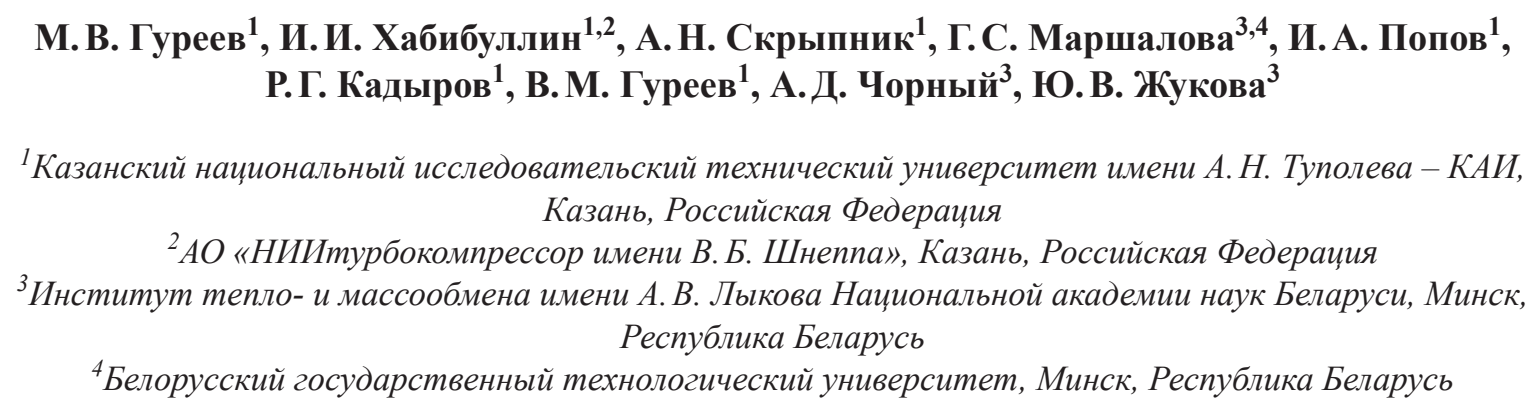

ОПРЕДЕЛЕНИЕ РАЦИОНАЛЬНЫХ КОМПОНОВОЧНЫХ РЕШЕНИЙ
ДЛЯ АППАРАТА ВОЗДУШНОГО ОХЛАЖДЕНИЯ МАСЛА
СИСТЕМ СМАЗКИ КОМПРЕССОРНЫХ УСТАНОВОК
С ИСПОЛЬЗОВАНИЕМ МЕТОДОВ ФИЗИЧЕСКОГО
И ЧИСЛЕННОГО МОДЕЛИРОВАНИЯ

Аннотация. С помощью методов численного моделирования исследованы тепло- и гидравлические параметры аппаратов воздушного охлаждения масла (ABOM) при изменении геометрии проточной части для снижения аэродинамического сопротивления воздушного тракта АВОМ и повышения эффективности охлаждения масла. Для этого на основе методов численного моделирования конвективного теплообмена разработана и апробирована методика расчетов, применимая к широкому классу теплообменных аппаратов, в том числе состоящих из секций оребренных плоских труб, полученных методом экструзии с последующей обработкой методом деформирующего резания. Отличительной особенностью методики является представление оребренной части теплопередающей поверхности в виде пористых вставок. Разработанная методика позволяет уменьшить требования к оборудованию для численного моделирования и снизить время расчетов. Результаты численного моделирования хорошо согласуются с результатами эксперимента; их анализ показывает, что тепловая мощность маслоохладителя вследствие выявленных конструктивных недостатков воздушного тракта АВОМ на 19 \% меньше проектного значения. На основе численных исследований выработан ряд рекомендаций по дальнейшему совершенствованию компоновочных решений для аппарата воздушного охлаждения масла с целью повышения его тепловой эффективности и аэродинамического совершенства. В частности, предложено установить новые лопатки вентиляторов для повышения их производительности; изменить конструкцию выходного воздушного клапана (жалюзи), исключив перегородку, частично затеняющую проходное сечение нижнего вентилятора; изменить форму нижнего коллектора маслоохладителя с целью обеспечения равномерного профиля скорости на входе в охлаждающие секции. Перспективным техническим решением, приводящим к увеличению общей производительности маслоохладителя, может быть последовательная схема подключения теплообменных секций. Эффективность всех предложенных технических решений может быть оценена с помощью методов численного моделирования, без создания дорогостоящей пилотной установки.

Ключевые слова: аппарат воздушного охлаждения, маслоохладитель, гидравлические потери, коэффициент конвективного теплообмена, численное моделирование

Для цитирования: Определение рациональных компоновочных решений для аппарата воздушного охлаждения масла систем смазки компрессорных установок с использованием методов физического и численного моделирования / М. В. Гуреев [и др.] // Вес. Нац. акад. навук Беларусі. Сер. фіз.-тэхн. навук. - 2020. - Т. 65, №2. - С. $215-223$. https://doi.org/10.29235/1561-8358-2020-65-2-215-223 
216 Proceedings of the National Academy of Sciences of Belarus. Physical-technical series, 2020, vol. 65, no. 2, pp. 215-223

Mikhail V. Gureev ${ }^{1}$ IImir I. Khabibullin ${ }^{1,2}$, Artyom N. Skrypnik ${ }^{1}$, Galina S. Marshalova ${ }^{3,4}$, Igor A. Popov, Ruslan G. Kadyrovi', Viktor M. Gureev ${ }^{1}$, Andrei D. Chorny ${ }^{3}$, Yuliya V. Zhukova ${ }^{3}$

\author{
${ }^{1}$ Kazan National Research Technical University named after A. N. Tupolev - KAI, Kazan, Russian Federation \\ ${ }^{2}$ JSC "NIIturbokompressor named after V.B. Schnepp", Kazan, Russian Federation \\ ${ }^{3}$ A. V. Luikov Heat and Mass Transfer Institute of the National Academy of Sciences of Belarus, Minsk, Republic of Belarus \\ ${ }^{4}$ Belarusian State Technological University, Minsk, Republic of Belarus
}

\title{
USE OF EXPERIMENTAL AND NUMERICAL SIMULATION METHODS FOR RATIONAL DESIGN OF THE AIR COOLING APPARATUS FOR LUBRICATION SYSTEMS OF COMPRESSORS
}

Abstract. The objective of the present work was to study heat and hydraulic parameters of an air cooling apparatus of oil (ACAO), whose geometry of its flow-through part is changed to decrease hydraulic losses in its air conduit and to increase the cooling efficiency of oil. Using numerical simulation methods of heat transfer, we have developed and tested the computational techniques applied in a wide class of heat exchange apparatuses, including those consisting of the sections of finned flat tubes manufactured by extrusion with subsequent deforming cutting. We have proposed to make a finned part of a heat-exchange surface in the form of porous inserts. This has allowed us to reduce numerical simulation equipment requirements and to decrease computational time. Predicted results well agree with experimental data; their analysis shows that the calculated value of thermal performance of the oil cooler due to the revealed construction drawbacks of the air conduit is by $19 \%$ less than that of the designed one. Based on the results of the numerical simulation studies, a number of recommendations have been made how to improve the layout inside the air cooling apparatus for oil in order to enhance its thermal performance and aerodynamic quality. In particular, we have proposed to mount new fan blades to enhance its performance; to change the construction of the air outlet valve by taking away a baffle that partially overshadows the exit area of the bottom fan; to modify the shape of the bottom collector of the oil cooler in order to make a uniform velocity profile at the entrance of cooling sections. Connecting in series heat exchange sections may be a perspective engineering decision. The outcomes of all proposed engineering decisions can be assessed by numerical simulation methods that will allow us not to design expensive equipment.

Keywords: air cooling apparatus, oil coolant, hydraulic losses, convective heat transfer coefficient, numerical simulation

For citation: Gureev M. V., Khabibullin I. I., Skrypnik A. N., Marshalova G. S., Popov I. A., Kadyrov R. G., Gureev V. M., Chorny A. D., Zhukova Y. V. Use of experimental and numerical simulation methods for rational design of the air cooling apparatus for lubrication systems of compressors. Vestsi Natsyyanal'nai akademii navuk Belarusi. Seryya fizika-technichnych navuk = Proceedings of the National Academy of Sciences of Belarus. Physical-technical series, 2020, vol. 65 , no. 2, pp. 215-223 (in Russian). https://doi.org/10.29235/1561-8358-2020-65-2-215-223

Введение. К современному теплотехнологическому оборудованию предъявляются повышенные требования по компактности и эффективности [1]. Повышая эффективность за счет применения методов интенсификации теплообмена, а также развивая поверхность теплообмена ресурсосберегающими методами (например, методом деформирующего резания), можно снизить металлоемкость и, как следствие, стоимость теплообменного оборудования при сохранении мощности или массогабаритных характеристик [2].

Аппараты воздушного охлаждения (ABO) используются на объектах по транспортировке и переработке природного газа, в системах оборотного водоснабжения электростанций, нефтеперерабатывающих заводах, нефтехимических комплексах и т.д. Объем мирового рынка АВО различного типа (вентиляторные, башенные, грунтовые и т.д.) оценивался в 1,2 млрд долларов США в 2018 г. и, как ожидается, увеличится в среднем на 10,8 \% с 2019 по 2025 г. В настоящее время только в России эксплуатируется около 52 тыс. АВО с установленной мощностью привода вентиляторов порядка 2,1-106,0 кВт.

Для эффективной работы винтовые и поршневые компрессоры используют масло определенной вязкости и консистенции, которые зависят от его температуры. При недостаточном охлаждении масла в компрессоре может начаться процесс его разложения, что негативно скажется на работоспособности компрессорного оборудования вплоть до выхода его из строя. Для уменьшения затрат на ремонт холодильных компрессоров следует правильно спроектировать масляный контур. Стандартный масляный контур компрессорного оборудования любой конструкции включает в себя систему контроля температуры масла, поэтому если температура выше установленной, то масло направляется в охладитель; если ниже, то поступает в блок компрессора.

Постановка задачи. В патенте Российской Федерации на полезную модель № 190872 «Аппарат воздушного охлаждения масла» (авторы - Р.М. Низамутдинов, И.И. Хабибуллин, Р.Г. Кадыров) предложена конструкция аппарата, предназначенного для охлаждения масла, циркулирующего в системе смазки компрессорных установок и газоперекачивающих агрегатов, функционирующих в условиях низких температур. Конструкция позволяет обеспечить рав- 
номерный прогрев охлаждающих секций маслоохладителя аппарата воздушного охлаждения масла (ABOM) за счет повышения эффективности процесса внутренней рециркуляции как на стадии обеспечения предпусковых условий, так и в режиме работы АВОМ при низких температурах окружающего воздуха (рис. 1).

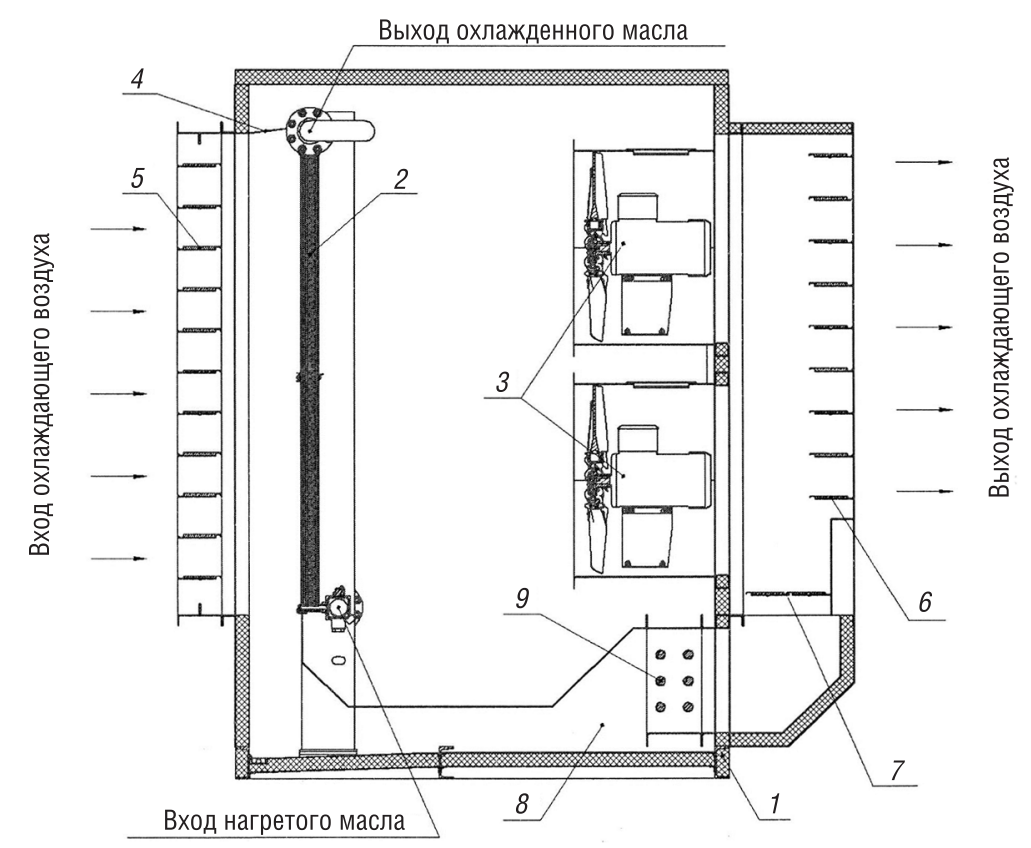

Рис. 1. Аппарат воздушного охлаждения масла: 1 - корпус, 2 - маслоохладитель с теплообменными секциями, 3 - осевые вентиляторы с электроприводами, 4 - направляющая перегородка, 5-7 - управляемые клапаны, 8 - канал рециркуляции, 9 - электронагреватель

Fig. 1. Oil air cooling apparatus: 1 - body, 2 - heat exchange oil cooler, 3 - axial fans with electric drives, 4 - baffle, 5-7 - controllable valves, 8 recirculation channel, 9 - electric heater

Маслоохладитель для предлагаемого АВОМ предполагается изготавливать с использованием оребренных плоских теплообменных труб из алюминиевого сплава, получаемых методами экструзии и деформирующего резания. Схема и внешний вид пилотного образца теплообменной секции представлены на рис. 2.

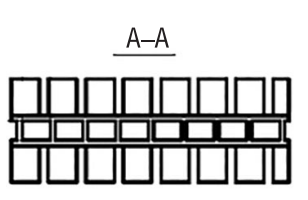

(a)

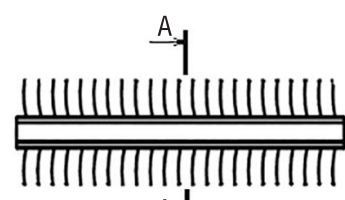

(b)

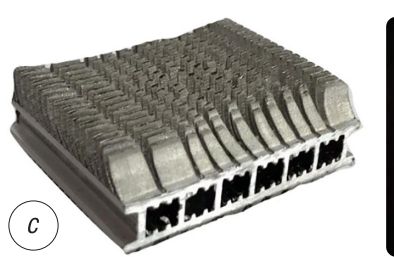

(c)

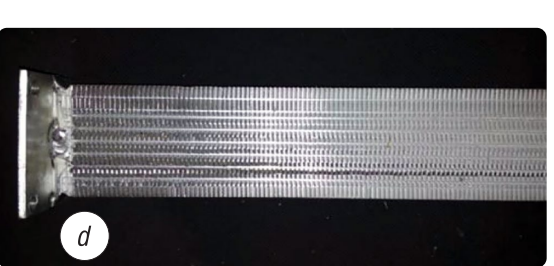

Рис. 2. Поперечное $(a)$, продольное $(b)$ сечение и внешний вид $(c, d)$ теплообменной секции

Fig. 2. Transverse (a), longitudinal (b) cross-sections and heat transfer section design $(c, d)$

В [3-5] на основе экспериментального исследования и сравнительного анализа по различным критериям эффективности обоснован и произведен выбор рациональных геометрических параметров образцов теплообменной секции АВО на основе данных теплообменных труб, обеспечивающих при фиксированных энергозатратах привода АВОМ снижение массогабаритных параметров теплообменной секции.

В последнее время при проектировании технических устройств в дополнение к инженерным подходам все чаще используются современные методы вычислительной гидрогазодинамики (Computational Fluid Dynamics - CFD). Применение методов численного моделирования 
позволяет не только проектировать технические устройства, в частности системы охлаждения, но и оптимизировать их отдельные узлы, а также детально оценивать влияние различных режимных и конструктивных параметров и выявлять рациональные с точки зрения теплогидравлической эффективности конструкции. Кроме того, использование указанных методов дает возможность снизить затраты, связанные с постановкой натурных теплофизических экспериментов.

В [6] предложен метод расчета поверхности охлаждения радиатора, позволяющий, во-первых, оценить пористость пучка труб в радиаторе и, во-вторых, учесть в расчетных формулах неравномерность теплооотдачи по глубине сердцевины радиатора. Используя эти идеи, на основе методов численного моделирования конвективного теплообмена была разработана и апробирована методика расчетов [7], применимая к широкому классу теплообменных аппаратов, включая АВОМ. Отличительной особенностью методики является представление оребренной части теплопередающей поверхности в виде пористых вставок для исключения необходимости описания расчетной сеткой мелких пластин и ребер. Разработанная методика позволяет уменьшить требования к оборудованию для численного моделирования и снизить время расчетов.

Методами численного моделирования в [8-10] проведено исследование теплогидравлических характеристик АВОМ при заданных геометрических параметрах маслоохладителя и всей проточной части АВОМ. Однако полученные результаты недостаточны для оптимизации геометрических параметров рассматриваемой конструкции. Целью представленной работы является исследование методами численного моделирования тепло- и гидравлических параметров АВОМ при изменении геометрии проточной части для снижения аэродинамического сопротивления воздушного тракта АВОМ и повышения эффективности охлаждения масла.

Численное моделирование теплогидравлических характеристик ядра маслоохладителя и АВОМ. На первом этапе была проведена верификация расчетной модели и алгоритма численного решения с использованием экспериментальных данных [12]. Объектом, позволившим верифицировать расчетный алгоритм, являлась модель теплообменной матрицы (ядра) маслоохладителя АВОМ, сконструированная на основе одного из вариантов геометрии плоских ореб-

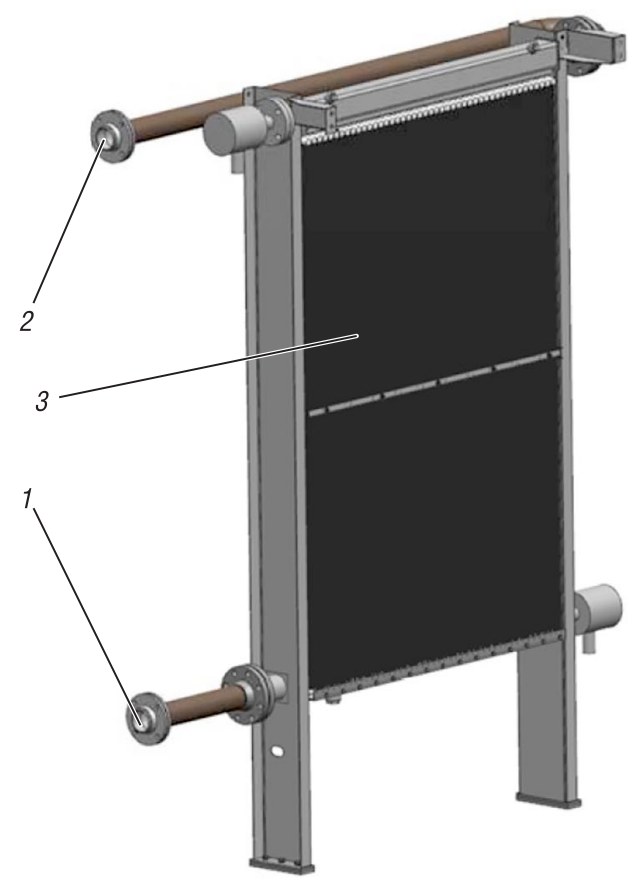

Рис. 3. СAD-модель теплообменной секции маслоохладителя аппарата воздушного охлаждения масла: 1 - подвод масла, 2 - отвод масла, 3 - оребренные плоские трубы

Fig. 3. CAD-model of the heat exchange section of the cooler of an air cooling apparatus of oil: 1 - oil input, 2 - oil output, 3 - finned flat tubes ренных теплообменных труб из алюминиевого сплава, получаемых методами экструзии и деформирующего резания [3]. Модель теплообменной матрицы (ядра) маслоохладителя АВОМ внешне омывалась потоком воздуха, внутри ее было реализовано течение масла. CAD-модель теплообменной матрицы (ядра) маслоохладителя ABOM показана на рис. 3.

Решались уравнения Навье-Стокса, осредненные по Рейнольдсу, уравнение неразрывности и уравнение энергии, сформулированное в терминах энтальпии. Для замыкания уравнений Рейнольдса была использована к- $\omega$ модель переноса сдвиговых напряжений Ментера в стандартной формулировке [12] совместно с пристеночной функцией Standart Scaleble, применение которой позволило получить результаты, наиболее близкие к экспериментальным данным.

В процессе решения сходимость задачи контролировалась уровнем погрешности. Для давления и скоростей минимальный уровень погрешности составлял $10^{-3}$, для температуры $-10^{-5}$. Расчеты прекращались по достижении погрешности для поправок давления $10^{-4}$, для энтальпии (уравнение энергии) $-10^{-8}$. Требуемая сходимость и установление постоянных значений основных интегральных параметров достигалась в пределах 1000 итераций.

Теплофизические свойства воздуха задавались: для плотности - согласно закону несжимаемого идеального 
газа, для вязкости - согласно закону Сазерленда; для коэффициента теплопроводности - полиномиальной зависимостью от температуры. Теплофизические свойства масла - в виде кусочнолинейных зависимостей.

Задача решалась в сопряженной постановке. Задавались следующие граничные условия: среднемассовые расходы на входе в контур воздуха и в контур масла; условие нулевого среднеинтегрального давления на выходах из контуров воздуха и масла; коэффициенты пористости характерной части контура воздуха; коэффициенты проницаемости секции; температура на входе контур воздуха и в контур масла. Стенки корпуса АВОМ предполагались теплоизолированными. Для замыкания модели пористого тела применялись материалы исследований потерь давления и тепловой эффективности (мощности) ядра маслоохладителя от расхода в различных секциях [3]. В ядре теплообменника маслоохладителя для моделирования процесса теплопередачи между контурами внешнего воздуха и масла использовалась модель двойной ячейки. Для учета неравномерности распределения скорости теплоносителей на входе в ядро маслоохладителя изза коллекторов была использована модель теплообменного аппарата двойной ячейки (dual cell heat exchanger model).

Результаты численного моделирования показали, что значения потерь полного давления по воздушному тракту выше экспериментальных на 4,2 \%; по тракту масла - ниже экспериментальных на $1,3 \%$; оцененная в численном моделировании тепловая мощность оказалась ниже экспериментально полученной на 0,4 \%, что позволяет считать разработанный подход корректным.

Для численного моделирования теплогидравлических характеристик всего блока АВОМ coздана трехмерная CAD-модель, представленная на рис. 4.
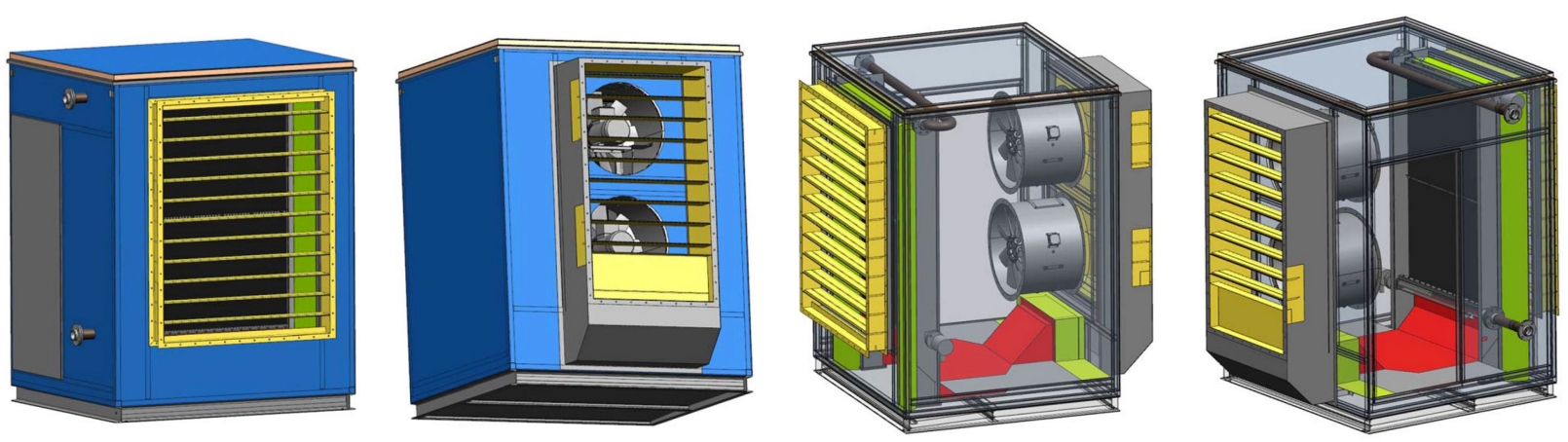

Рис. 4. CAD-модель элементов, входящих в состав аппарата воздушного охлаждения масла

Fig. 4. CAD-model of air cooling apparatus of oil elements

С целью исключения влияния граничных условий на гидродинамические, газодинамические и тепловые процессы в блоке охлаждения (рис. $5, a$ ) расчетная модель была дополнена входной и выходной областями.
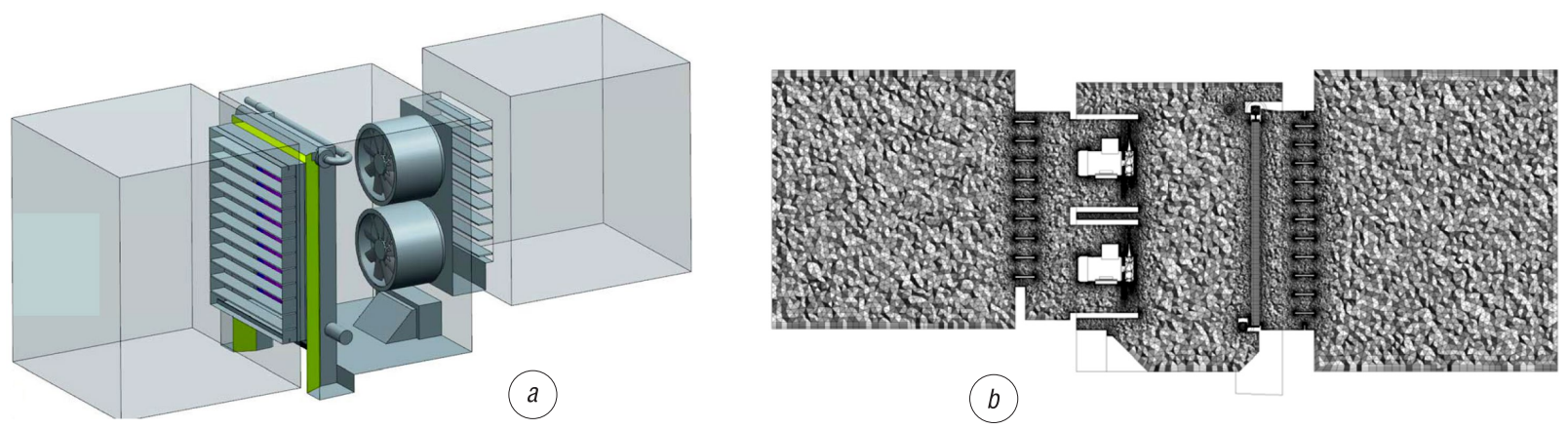

Рис. 5. CAD-модель элементов аппарата воздушного охлаждения масла с дополнительными входной и выходной областями $(a)$ и фрагмент расчетной сетки $(b)$

Fig. 5. CAD-model of the elements of air cooling apparatus of oil with additional inlet and outlet computational domains (a) and the computational grid fragment $(b)$ 
Для создания расчетной сетки блока охлаждения (блока маслоохладителя) использовался генератор сеток ANSYS Meshing. Вращение вентиляторов имитировалось вращающейся локальной системой координат. Итоговая конечно-объемная сетка состояла из 20 млн тетрагексагональных и гибридных элементов (рис. $5, b$ ). Максимальный размер ячейки поверхностной сетки был равен 10 мм; максимальный размер объемной ячейки - 10 мм, минимальный - 1 мм. Для корректного описания всех особенностей геометрии элементов блока маслоохладителя при разработке расчетной сетки применялась опция локального сгущения. Для описания пограничного слоя потока воздуха в пристеночных областях генерировался пятиуровневый слой, состоящий из призматических ячеек, с коэффициентом роста 1,2 .

Обсуждение полученных результатов. Результаты численного моделирования показали [9], что часть потока воздуха равномерно проходит через маслоохладитель, далее направляется в зону вентиляторов, образуя застойные зоны в нижней и верхней задней частях АВОМ (выделены черным овалом, рис. $6, a$ ). Эти застойные зоны вносят незначительный вклад в потери давления по воздушному тракту. Распределение скорости по высоте маслоохладителя имеет однородный характер, за исключением участка, расположенного в нижней части маслоохладителя (рис. $6, b)$, формируя в этой области значения скорости ниже среднего из-за влияния формы и расположения нижнего коллектора. Неравномерное распределение скорости воздуха по высоте маслоохладителя (рис. $6, c$ ) приводит к неравномерности распределения температуры в АВОМ (рис. $6, d$ ). Результаты численного моделирования показали, что тепловая мощность маслоохладителя вследствие выявленных конструктивных недостатков воздушного тракта АВОМ на $19 \%$ меньше проектного значения.
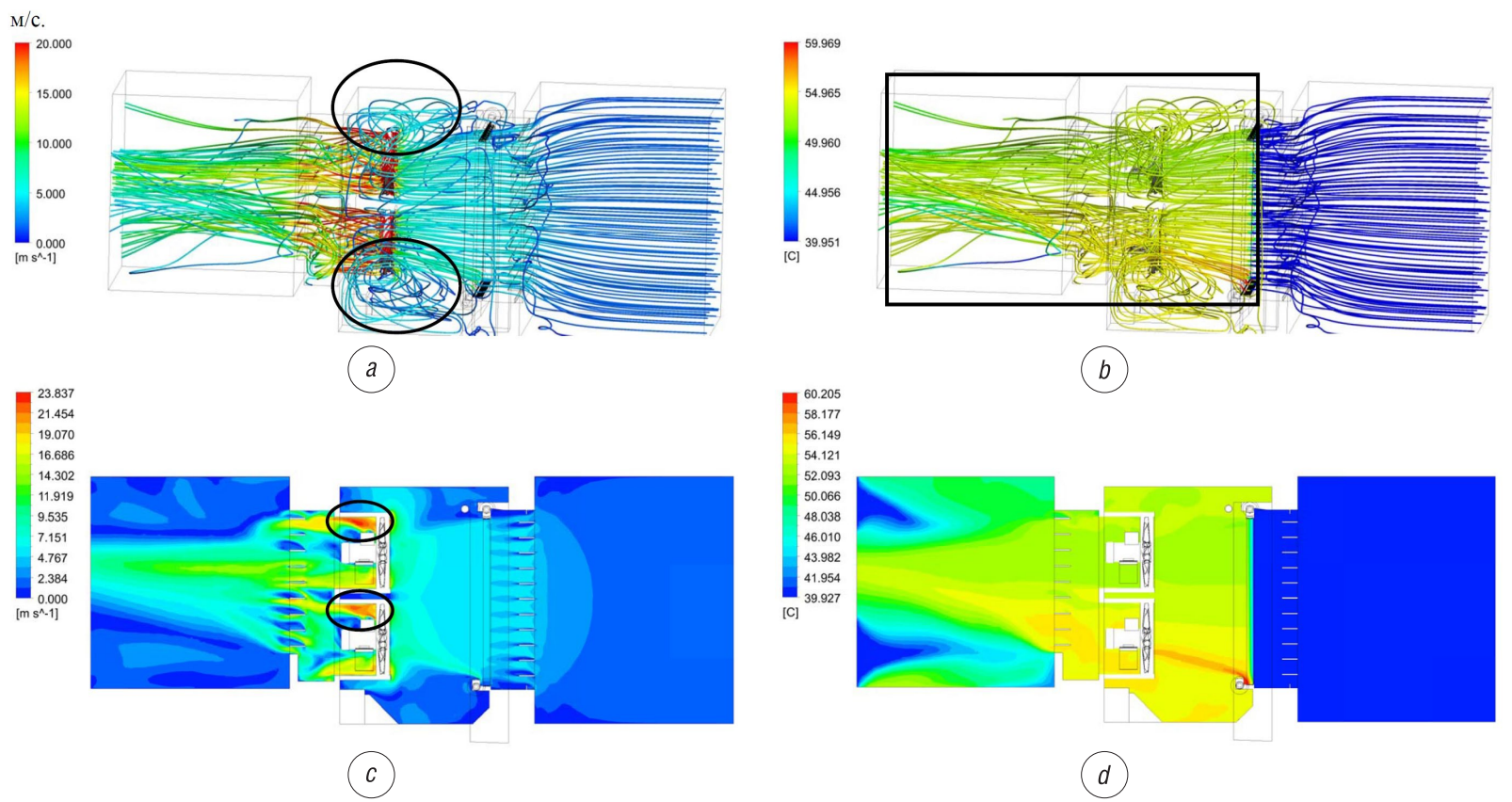

Рис. 6. Линии тока $(a)$, изотермы $(b)$, поле скоростей $(c)$ и поле температур $(d)$ в воздушном тракте аппарата воздушного охлаждения масла

Fig. 6. Streamlines (a), isotherms $(b)$, velocity $(c)$ and temperature $(d)$ in the air conduit of air cooling apparatus of oil

Исходя из полученных результатов численного исследования, с целью повышения эффективности было рекомендовано установить маслоохладитель с большей теплопередающей поверхностью. Для повышения эффективности АВОМ предложено параллельно подключить две теплообменные секции (ядра) маслоохладителя в составе аппарата. Чтобы изменить геометрию АВОМ, нами проведено численное исследование его теплогидравлических характеристик. Однако полученные результаты показали, что данное техническое решение не дает требуемого результата: тепловая мощность маслоохладителя вследствие выявленных конструктивных недостатков воздушного тракта АВОМ на 10,6 \% меньше проектного значения. 
Однако использование методов численного моделирования для анализа эффективности функционирования АВОМ позволило сформулировать ряд рекомендаций по изменению воздушного тракта АВОМ и наметить пути для перспективных исследований. В частности, предложено установить новые лопатки вентиляторов для повышения их производительности; изменить конструкцию выходного воздушного клапана (жалюзи), исключив перегородку, частично затеняющую проходное сечение нижнего вентилятора; изменить форму нижнего коллектора маслоохладителя с целью обеспечения равномерного профиля скорости на входе в охлаждающие секции. Перспективным техническим решением, приводящим к увеличению общей производительности маслоохладителя, может быть последовательная схема подключения теплообменных секций (ядер). Недостатком этого решения является увеличение гидравлических потерь в масляном тракте и, как следствие, снижение расхода теплоносителя через масляный насос.

Заключение. На основе методов численного моделирования конвективного теплообмена разработана и апробирована методика расчетов, применимая к широкому классу теплообменных аппаратов, в том числе состоящих из секций оребренных плоских труб, полученных методом экструзии с последующей обработкой методом деформирующего резания. Отличительной особенностью методики является представление оребренной части теплопередающей поверхности в виде пористых вставок. Разработанная методика позволяет уменьшить требования к оборудованию для численного моделирования и снизить время расчетов. Результаты численного моделирования хорошо согласуются с результатами эксперимента.

Проведенные численные исследования теплогидравлических характеристик АВОМ показали несоответствие проектным значениям по тепловой мощности и выявили причины этого несоответствия. Предложено техническое решение для другой компоновки маслоохладителя в АВОМ.

При параллельном подключении к АВОМ двух секций маслоохладителей результаты численного моделирования теплогидравлических характеристик показали несоответствие проектным значениям по тепловой мощности.

На основе численных исследований разработан ряд рекомендаций по дальнейшему совершенствованию компоновочных решений АВОМ для повышения его тепловой эффективности и аэродинамического совершенства.

\section{Благодарности}

Работа выполнена при финансовой поддержке Российского фонда фундаментальных исследований (грант 19-58-04006) и Белорусского республиканского фонда фундаментальных исследований (гранты Т19РМ-076 и Ф18Р-035).

\section{Acknowledgements}

The present work was financially supported by the Russian Foundation for Basic Research (project No 19-5804006) and by the Belarusian Republican Foundation for Fundamental Research (projects T19RM-076 and F18R-035).

\section{Список использованных источников}

1. Попов, И.А. Физические основы и промышленное применение интенсификации теплообмена: интенсификация теплообмена / И. А. Попов, Х. М. Махянов, В. М. Гуреев; под общ. ред. Ю. Ф. Гортышова. - Казань: Центр инновац. технологий, 2009. - 560 с.

2. Перспективные методы интенсификации теплообмена для теплоэнергетического оборудования / И. А. Попов [и др.] // Энергетика Татарстана. - 2011. - № 1. - С. 25-29.

3. Экспериментальное исследование теплогидравлических характеристик оребренных плоских труб аппарата воздушного охлаждения масла / С.В. Тиунов [и др.] // Вестн. Казан. гос. техн. ун-та им. А.Н. Туполева. - 2019. - Т. 75, №3. - С. 10-15.

4. Скрыпник, А.Н. Экспериментальное исследование теплогидравлических характеристик оребренных плоских труб аппарата воздушного охлаждения масла / А.Н. Скрыпник // Труды XXIV Международной молодежной научной конференции «Туполевские чтения». - Казань: изд-во ИП А. Р. Сагиева. - 2019. - Т. 2. - С. $277-281$.

5. Экспериментальное исследование характеристик оребренных плоских труб / Г.С. Маршалова [и др.] // Будущее машиностроения России: тр. 12-й Всерос. конф. молодых ученых и специалистов с междунар. участием. М.: Изд-во МГТУ им. Н.Э. Баумана, 2019. - С. 532-536.

6. Якубович, А.И. К вопросу расчета поверхности охлаждения многорядных радиаторов тракторов «Беларус»/ А. И. Якубович, В.Е. Тарасенко // Вестн. ГГТУ им. П. О. Сухого. - 2010. - № 2. - С. 49-58.

7. Маршалова, Г.С. Использование методов численного моделирования для расчета радиатора охлаждения транспортных средств / Г. С. Маршалова, Т. А. Баранова, А. Д. Чорный // Труды XXIV Международной молодежной научной конференции «Туполевские чтения». - Казань: изд-во ИП А. Р. Сагиева. - 2019. - Т. 2. - С. $252-256$. 
8. Хабибуллин, И.И. Интенсификация тепломассообмена в аппаратах воздушного охлаждения / И. И. Хабибуллин, Р. М. Низамутдинов, Р. Г. Кадыров // Вестн. Казан. гос. техн. ун-та им. А. Н. Туполева. - 2018. - Т. 74, № 4. - С. 55-60.

9. Аппараты воздушного охлаждения масла для компрессорных установок. Повышение эффективности / Р. Г. Кадыров [и др.] // Компрессорная техника и пневматика. - 2019. - № 1. - С. 35-42.

10. Численное моделирование процессов теплообмена в аппарате воздушного охлаждения масла / И.И. Хабибуллин [и др.] // Газовая пром-сть. - 2019. - № 2. - С. 84-90.

11. Экспериментальное исследование теплогидравлических характеристик оребренных плоских труб аппарата воздушного охлаждения масла / С. В. Тиунов [и др.] // Энергетика. Изв. высш. учеб. заведений и энерг. объединений СНГ. - 2020. - Т. 63, № 2. - С. 138-151. https://doi.org/10.21122/1029-7448-2020-63-2-138-150

12. Menter, F. R. Zonal two equation k-w turbulence models for aerodynamic flows / F. R. Menter // $23^{\text {rd }}$ Fluid Dynamics, Plasmadynamics, and Lasers Conference, 1993. - №2906. - P. 1-21. https://doi.org/10.2514/6.1993-2906.

\section{References}

1. Popov I. A., Makhyanov Kh. M., Gureyev V. M. GortyshovYu. F. (ed.) Physical Basis and Industrial Application of Heat Transfer Enhancement: in 'Heat Transfer Enhancement'. Kazan, Tsentr innovatsionnykh tekhnologii Publ., 2009. 560 p. (in Russian).

2. Popov I. A., Yakovlev A. B., Schelchkov A. V., Ryzhkov D. V., Obukhova L. A. Promising methods of heat transferen hancement for heat power equipment. Energetika Tatarstana [Energy of Tatarstan], 2011, no. 1, pp. 25-29 (in Russian).

3. Tiunov S. V., Skrypnik A. N., Marshalova G. S., Gureev V. M., Popov I. A. Experimental study of thermal-hydraulic performance of finned heat exchanger flat pipes for oil air-cooler. Vestnik Kazanskogo gosudarstvennogo tehnicheskogo universiteta imeni A. N. Tupoleva = Vestnik KGTU im. A.N.Tupoleva, 2019, vol. 75, no. 3, pp. 10-15 (in Russian).

4. Skrypnik A. N. Experimental study of the thermohydraulic characteristics of finned flat tubes of an oil-air cooler. Trudy XXIV Mezhdunarodnoj molodozhnoj nauchnoj konferentsii “Tupolevskie chteniya". T. 2[ Proceedings of the $24^{\text {th }}$ International Youth Scientific Conference "Tupolevskie chteniya”. Vol. 2]. Kazan, 2019, pp. $277-281$ (in Russian).

5. Marshalova G. S., Popov I. A., Skrypnik A. N., Tiunov S. V. Experimental study of the characteristics of finned flat tubes. Budushcheye mashinostroyeniya Rossii: trudy 12-i Vserossiyskoi konferentsii molodykh uchenykh $i$ spetsialistov s mezhdunarodnym uchastiyem [The Future of Russian Engineering: Proceedings of the $12^{\text {th }}$ All-Russian Conference of Young Scientists and Specialists with International Participation]. Moscow, Bauman Publishing House, 2019, pp. 532-536 (in Russian).

6. Yakubovich A. I., Tarasenko V. E. On the issue of calculating the cooling surface of multi-row radiators of tractor "Belarus". Vestnik GGTU imeni P. O. Sukhogo [Bulletin of the Sukhoi State Technical University of Gomel], 2010, no. 2, pp. 49-58 (in Russian).

7. Marshalova G. S., Baranova T. A., Chorny A. D. Using of numerical simulation methods to calculate the cooling radiator for vehicles. Trudy XXIV Mezhdunarodnoi molodozhnoi nauchnoi konferentsii "Tupolevskie chteniya". T. 2 [Proceedings of the 24th International Youth Scientific Conference "Tupolevskie chteniya". Vol. 2]. Kazan, 2019, pp. 252-256 (in Russian).

8. Habibullin I. I., Nizamutdinov R. M., Kadyrov R. G. Heat and mass transfer enhancement in air coolers. Vestnik Kazanskogo gosudarstvennogo tehnicheskogo universiteta imeni A. N. Tupoleva [Vestnik KGTU im. A.N. Tupoleva], 2018, vol. 74, no. 4, pp. 55-60 (in Russian).

9. Kadyrov R. G., Habibullin I. I., Nizamutdinov R. M., Paranin Yu. A. Oil-air coolers for compressors. Efficiency enhancement. Kompressornaya tehnika i pnevmatika = Compressors and Pneumatics, 2019, no. 1, pp. 35-42 (in Russian).

10. Habibullin I. I., Nizamutdinov R. M., Kadyrov R. G., Nikolaenko I. V., Gureev M. V., Tiunov S. V.Numerical simulation of heat transfer processes in an oil-air cooler. Gazovaya promyshlennost' = Gas Industry, 2019, no. 2, pp. 84-90 (in Russian).

11. Tiunov S. V., Skrypnik A. N., Marshalova G. S., Gureev V. M., Popov I. A., Kadyrov R. G., Chorny A. D., Zhukova Yu. V. Experimental study of the thermohydraulic characteristics of finned flat tubes of an oil-air cooler. Energetika. Proceedings of CIS higher education institutions and power engineering associations, 2020, vol. 63, no. 2, pp. 138-151 (in Russian). https://doi.org/10.21122/1029-7448-2020-63-2-138-150

12. Menter F. R. Zonal two equation k-w turbulence models for aerodynamic flows. $23^{\text {rd }}$ Fluid Dynamics, Plasmadynamics, and Lasers Conference, 1993, no. 2906, pp. 1-21. https://doi.org/10.2514/6.1993-2906

\section{Информация об авторах}

Гуреев Михаил Викторович - научный сотрудник, Казанский национальный исследовательский технический университет имени А.Н. Туполева - КАИ (ул. К. Маркса, 10, 420111, Казань, Российская Федерация). E-mail: gureev.mv@gmail.com

Хабибуллин Ильмир Ильдарович - кандидат технических наук, ведущий инженер, АО «НИИтурбокомпрессор имени В.Б. Шнеппа» (Сибирский тракт, 40, 420029, Казань, Российская Федерация); Казанский национальный исследовательский технический университет имени А.Н. Туполева - КАИ (ул. К. Маркса, 10, 420111, Казань, Российская Федерация). E-mail: rim31i490@mail.ru

\section{Information about the authors}

Mikhail V. Gureev - Research Associate, Kazan National Research Technical University named after A.N. Tupolev KAI (10, K. Marx Str., 420111, Kazan, Russian Federation). E-mail: gureev.mv@gmail.com

Ilmir I. Khabibullin - Ph. D. (Engineering), Leading Engineer, JSC "NIIturbokompressor named after V.B. Schnepp" (40, Siberian Tract, 420029, Kazan, Russian Federation); Kazan National Research Technical University named after A. N. Tupolev - KAI (10, K. Marx Str., 420111, Kazan, Russian Federation). E-mail: rim31i490@mail.ru 
Скрылиик Артем Николаевич - аспирант, ассистент, Казанский национальный исследовательский технический университет имени А.Н. Туполева - КАИ (ул. К. Маркса, 10, 420111, Казань, Российская Федерация). E-mail: anskrypnik@kai.ru

Маршалова Галина Сергеевна - кандидат технических наук, ассистент, Белорусский государственный технологический университет (ул. Свердлова, 13a, 220006, Минск, Республика Беларусь); научный сотрудник лаборатории турбулентности, Институт теплои массообмена имени А.В. Лыкова Национальной академии наук Беларуси (ул. П. Бровки 15, 220072, Минск, Республика Беларусь). E-mail: galiana.sidorik@gmail.com

Попов Игорь Александрович - член-корреспондент Академии наук Республики Татарстан, доктор технических наук, профессор, Казанский национальный исследовательский технический университет имени А.Н. Туполева - КАИ (ул. К. Маркса, 10, 420111, Казань, Российская Федерация). E-mail: popov-igor-alex@yandex.ru. https:/orcid.org/0000-0002-1700-7896

Кадыров Руслан Газинурович - аспирант, Казанский национальный исследовательский технический университет имени А.Н. Туполева - КАИ (ул. К. Маркса, 10, 420111, Казань, Российская Федерация). E-mail: adres. krg@mail.ru

Гуреев Виктор Михайлович - доктор технических наук, профессор, Казанский национальный исследовательский технический университет имени А.Н. Туполева - КАИ (ул. К. Маркса, 10, 420111, Казань, Российская Федерация). E-mail: viktor.gureev@kai.ru. https:/orcid. org/0000-0003-1229-8417

Чорнылй Андрей Дмитриевич - кандидат физико-математических наук, доцент, заведующий лабораторией турбулентности, Институт тепло- и массообмена имени А.В. Лыкова Национальной академии наук Беларуси (ул. П. Бровки 15, 220072, Минск, Республика Беларусь). E-mail: anchor@hmti.ac.by. https://orcid.org/0000-00034716-6123

Жукова Юлия Владимировна - кандидат физикоматематических наук, доцент, ведущий научный сотрудник, лаборатория турбулентности, Институт теплои массообмена имени А.В. Лыкова Национальной академии наук Беларуси (ул. П. Бровки 15, 220072, Минск, Республика Беларусь). E-mail: julia_zhukova@rambler.ru. https://orcid.org/0000-0003-1219-6373
Artyom N. Skrypnik - Postgraduate Student, Assistant, Kazan National Research Technical University named after A. N. Tupolev - KAI (10, K. Marx Str., 420111, Kazan, Russian Federation). E-mail: anskrypnik@kai.ru

Galina S. Marshalova - Ph. D. (Engineering), Junior Researcher, Belarusian State Technological University (13a, Sverdlov Str., 220006, Minsk, Republic of Belarus); Scientific Researcher, Laboratory of Turbulence, A. V. Luikov Heat and Mass Transfer Institute of the National Academy of Sciences of Belarus (15, P. Brovka Str., 220072, Minsk, Republic of Belarus). E-mail: galiana.sidorik@gmail.com

Igor A. Popov-Corresponding Member of the Academy of Sciences of the Republic of Tatarstan, D. Sc. (Engineering), Professor, Kazan National Research Technical University named after A. N. Tupolev - KAI (10, K. Marx Str., 420111, Kazan, Russian Federation). E-mail: popov-igor-alex@yandex.ru. https://orcid.org/0000-0002-1700-7896

Ruslan G. Kadyrov - Postgraduate Student, Kazan National Research Technical University named after A. N. Tupolev - KAI (10, K. Marx Str., 420111, Kazan, Russian Federation). E-mail: adres.krg@mail.ru

Viktor M. Gureev - D. Sc. (Engineering), Professor, Kazan National Research Technical University named after A. N. Tupolev - KAI (10, K. Marx Str., 420111, Kazan, Russian Federation). E-mail: viktor.gureev@kai.ru. https:// orcid.org/0000-0003-1229-8417

Andrei D. Chorny - Ph. D. (Physics and Mathematics), Associate Professor, Head of the Laboratory of Turbulence, A. V. Luikov Heat and Mass Transfer Institute of the National Academy of Sciences of Belarus (15, P. Brovka Str., 220072, Minsk, Republic of Belarus). E-mail: anchor@hmti.ac.by. https://orcid.org/0000-0003-4716-6123

Yuliya V. Zhukova - Ph. D. (Physics and Mathematics), Associate Professor, Leading Researcher, Laboratory of Turbulence, A. V. Luikov Heat and Mass Transfer Institute of the National Academy of Sciences of Belarus (15, P. Brovka Str., 220072, Minsk, Republic of Belarus). E-mail: julia zhukova@rambler.ru. https://orcid.org/0000-0003-1219-6373 